\title{
EDUCAÇÃO NO/DO CAMPO: DESAFIOS E PERSPECTIVAS DE UMA ESCOLA NO CAMPO LOCALIZADA NO DISTRITO FEDERAL*
}

\section{RURAL EDUCATION: CHALLENGES AND PROSPECTS OF A RURAL SCHOOL IN THE FEDERAL DISTRICT \\ EDUCACIÓN EN EL CAMPO: RETOS Y PERSPECTIVAS DE UNA ESCUELA EN LA ZONA RURAL SITUADA EN EL DISTRITO FEDERAL}

Rodrigo Capelle Suess Acadêmico do Curso de Geografia pela Universidade Estadual de Goiás - Câmpus Formosa rodrigo.capellesuess@gmail.com

Hugo de Carvalho Sobrinho Acadêmico do Curso de Geografia pela Universidade Estadual de Goiás - Câmpus Formosa hugodecarvalho2009@hotmail.com

Rafael Gonçalves Bezerra Graduando de Licenciatura em Ciências Biológicas pelo Instituto Federal de Educação, Ciência e Tecnologia de Goiás ra.fagonalves@hotmail.com

RESUMO: A educação no/do campo surge como expectativa de uma proposta educativa que esteja emaranhada na cultura, tempos e ritmos dos sujeitos do campo em prol de uma sociedade justa que possa ser construída por todos e não imposta por poucos, uma sociedade na qual cidadãos tenham voz e respeito mútuos. Sendo assim, procurou-se, neste trabalho, discutir brevemente a educação no/do campo e as condições de vida no campo. Buscou-se apresentar e discutir os resultados da pesquisa para melhor compreender o contexto social, econômico e cultural no qual os alunos de uma escola no campo do Distrito Federal e suas famílias convivem, bem como fazer as considerações necessárias acerca dessa realidade. Dessa forma, o trabalho se reveste de uma pesquisa quali-quantitativa, pois essa mesclagem possibilita melhores instrumentos para desvendar os aspectos latentes da experiência dos sujeitos envolvidos. Observou-se que as famílias dos alunos vivem em condições bem simples, possuem baixa escolaridade e renda, e a maioria não tira o próprio sustento da terra que lhes pertence, mas cultivam plantas e animais para suplementar a renda e alimentação. Questões culturais, como a religiosidade, acabam influenciando nos hábitos cotidianos e no tratamento com a natureza. Detectou-se que a leitura e o estudo são hábitos que os alunos gostam de fazer, todavia um dos aspectos preocupantes foi o bullying na escola. Assim, considera-se esse trabalho relevante, pois sinaliza o cotidiano do aluno do campo na medida em que possibilita a valorização do contexto de vida de cada sujeito.

PALAVRAS-CHAVE: Educação no Campo. Ensino Fundamental. Percepções. Agricultura.

ABSTRACT: Education in the countryside arises as an expectative of an educational proposal that is embraced in culture, times and rhythms of the subjects of the countryside in favor of a fair society, which can be built by everyone and not imposed by a few, a society where citizens have voice and mutual respect. In this way, this work tried to briefly discuss rural education and living conditions. This work attempted to present and discuss the research's results to better understand the social, economic and cultural context in which students of a rural school of the Federal District and their families live, as make the necessary considerations round that reality. Thus, the work has qualitative and quantitative research, as this enables better blending tools to uncover the latent aspects of the experience of those involved. It was observed that students' families live in simple conditions, have low education and income, and most do not take proper sustenance of the land that belongs to them, but cultivate plants and animals to supplement their income and food. Cultural issues such as religion ultimately influence the daily habits and dealing with

Artigo recebido em fevereiro de 2014

Aprovado em março de 2014

Cad. Pes., São Luís, v. 21, n. 1, jan./abr. 2014. 


\section{artigo}

nature. It was found that reading and study habits are the things that students like to do, however one of the troubling aspects was the bullying at school. Then, it is considered a relevant work because it signs the students routine at the countryside as it enables the appreciation of the life context of each person.

KEYWORDS: Rural education. Elementary education. Perceptions. Farming.

RESUMEN: La educación en \de la zona rural surge como la expectativa de un enfoque educativo que está inmerso en la cultura, tiempos y los ritmos de los sujetos del campo en favor de una sociedad justa, que puede ser construida por todos y no sobrepuesta por unos pocos, una sociedad en la que los ciudadanos tienen voz y el respeto mutuo. Por lo tanto, tratamos de discutir brevemente este trabajo en condiciones de educación / de campo y de vida en el campo. Hemos tratado de presentar y discutir los resultados de la investigación para comprender mejor el contexto social, económico y cultural en el que viven los estudiantes de una escuela en el ámbito del Distrito Federal y de sus familias, y hacer las consideraciones necesarias que la realidad. Por lo tanto, el trabajo es la investigación cualitativa y cuantitativa, ya que esto permite una mezcla de herramientas para descubrir los aspectos latentes de la experiencia de los involucrados. Se observó que las familias de los estudiantes viven en condiciones simples, tienen bajo nivel de educación e ingresos, y la mayoría no recibe sustento adecuado de la tierra que les pertenece a ellos, sino a cultivar las plantas y los animales para complementar sus ingresos y alimentos. Las cuestiones culturales como la religión, en última instancia influyen en los hábitos diarios y en el tratamiento con la naturaleza. Se concluye que los hábitos de lectura y de estudio son lo que los estudiantes les gustan hacer, sin embargo uno de los aspectos preocupantes es el bullyning en las escuelas. Así, se considera éste un trabajo relevante porque representa el cotidiano del alumno de la zona rural permitiendo la valoración del contexto de vida de cada sujeto.

PALABRAS CLAVE: Educación rural. La educación primaria. Percepciones. Agricultura. 


\section{1 | Introdução}

Diante de aspectos relevantes do mundo atual e de suas constantes transformações que se refletem em sobreposições de culturas, aculturação, relações travadas entre sujeitos em diversos campos do conhecimento, sejam eles culturais, econômicos, tecnológicos ou sociais, todos acabam por influenciar nas concepções acerca da educação. Muito se espera das proposições, muito se espera de uma educação que possa transformar cidadãos, tanto da cidade, quanto do campo, em sujeitos falantes, participantes, críticos e atuantes que possam agir de forma ativa de maneira a contribuir para a transformação da sociedade.

A educação escolar nos moldes atuais está voltada mormente para um paradigma urbano. Doutro modo, a educação voltada para as comunidades que residem no campo ainda é pouco estudada e, nesse sentido, muitos enfoques podem ser explorados, mesmo porque o campo, nas representações das pessoas, é relegado à condição de um lugar atrasado e tradicional. Em defesa de uma educação para todos e considerando-se a centralidade e relevância que o lugar tem para os seres humanos que habitam no campo torna-se imprescindível o debate sobre o cenário no qual se encontra a educação no/do campo.

Este estudo se pauta em um cenário de desvalorização da educação no/do campo e de minorias envolvidas, quais sejam, os indígenas, quilombolas, camponeses, assentados, caiçaras e outros. Minorias que por condições históricas veem seus direitos renegados, sendo incluídos e marginalizados dentro de um sistema e ao mesmo tempo excluídos das condições mínimas de um cidadão, fazendo, assim, parte de uma sistemática fábrica de perversidades sociais (SANTOS, 2011).

Com efeito, os sujeitos do campo escolhidos para serem protagonistas desta análise são cidadãos de direito que por muito tempo tiveram renegados direitos mínimos, como é o caso da educação. O histórico das políticas públicas demonstra essa realidade que o Estado chega a reconhecer diretamente ao estabelecer as Diretrizes Nacionais para Educação no Campo.

Sendo assim, este trabalho teve como objetivo pesquisar informações que possam dar subsídios para melhor compreensão do cotidiano e mundo vivido dos alunos e de suas famílias no contexto de uma escola do campo, situada na Região Administrativa de Planaltina (DF). Dessa forma, o trabalho consistiu em uma pesquisa quali-quantitativa, pois essa mesclagem possibilita melhores instrumentos para desvendar os aspectos latentes da experiência dos sujeitos envolvidos. Para tal, a equipe gestora da escola foi contactada, momento no qual se pediu a autorização para a realização do trabalho.

A coleta de dados ocorreu por meio da observação da realidade da escola e da aplicação de questionários com perguntas abertas e fechadas, acompanhados de um Termo de Livre Consentimento para a participação na pesquisa. Foram escolhidas as turmas que, segundo a direção da unidade escolar, possuíam "maior maturidade" para responder ao questionário: 3o , 4 e 5ํanos da primeira fase da ensino fundamental.

Os questionários foram aplicados em sala de aula. Esta atividade durou em média 40 minutos, visto que os pesquisadores optaram por empreender uma leitura, questão por questão, junto com os discentes para que eventuais dúvidas pudessem ser dirimidas. O questionário destinado aos pais dos alunos foi entregue para que os alunos levassem para casa e trouxessem um dia depois, porém, devido ao fato de alguns alunos não terem entregado no dia seguinte, fizeram-se necessárias outras visitas à escola para recolher o questionário. Os dados obtidos foram analisados tanto sob o enfoque quantitativo quanto qualitativo, buscando os melhores fins que pudessem revelar qualidades a respeito da vida, gostos e concepções dos alunos e pais pesquisados.

$\mathrm{Na}$ apresentação do trabalho, as perspectivas e análises são tratadas do ponto de vista da educação no/do campo e da compreensão do cotidiano e mundo vivido dos alunos. Inicialmente, discute-se brevemente a educação no/do campo, as condições de vida no campo e o contexto 
socioeconômico no qual os sujeitos protagonistas deste estão inseridos; num segundo momento, apresentam-se e discutem-se os resultados da pesquisa, bem como se fazem as considerações necessárias.

\section{2 | Historicidade, contexto atual e desafios da educação no/do campo}

A trajetória histórica da educação desenvolvida no meio rural denuncia a forma com que os sujeitos do campo foram tratados e até hoje apresenta resquícios imateriais e materiais dessa conjuntura. Sendo assim, não faz sentido discutir a educação no/do campo olhando apenas para o momento atual, desconsiderando o seu processo de constituição.

Segundo Souza (2011), a luta por uma educação voltada para os camponeses surge juntamente com a luta pela terra, ações que foram empreendidas por meio de movimentos sociais. Para Fernandes (2006), a compreensão da origem do conceito de educação do campo dá-se por meio da compreensão da maneira pela qual essa educação nasceu, qual seja, das demandas dos movimentos camponeses em busca da construção de uma política educacional para os assentados da reforma agrária. Assim, compreende-se que essa educação é também um processo de reivindicação por melhorias e por mudanças na realidade do campo brasileiro.

Não basta apenas compreender a educação do/no campo no perímetro e competência das escolas que visam oferecer essa modalidade de educação. Uma vez que contexto em que vivem os camponeses - representando aqui a educação no campo - é fundamental para se compreender como a necessidade de uma educação voltada para os mesmos é construída coletivamente entre Poder Público, sociedade civil, movimentos sociais, intelectuais e os próprios camponeses.

Pensando assim, Caldart (2002a, p. 22) esclarece que "[...] não há como verdadeiramente educar os sujeitos do campo sem transformar as circunstâncias sociais desumanizantes, e sem prepará-los para serem os sujeitos destas transformações". Dessa forma, a educação do campo visa construir sujeitos conscientes de sua condição e capazes de se posicionar a favor dos interesses dos camponeses, de uma sociedade mais justa e contra as injustiças frente a um sistema reprodutor de desigualdades. Ademais, de maneira simultânea, enseja contribuir para a transformação da realidade vivenciada por esses sujeitos.

As escolas públicas localizadas no campo, e o próprio Governo, trataram por muito tempo e de certa forma ainda tratam esses sujeitos e o seu modo de vida como atrasados, além de importar uma imagem de progresso baseada na cidade e no sistema capitalista, o do ser humano consumista, detentor de riquezas. Nascimento (2004, p. 2) expõe que "um grande desafio a ser vencido na realidade social do meio rural são os muitos conceitos que qualificam ou desqualificam os habitantes do campo".

Um marco para a discussão e projeção da educação desenvolvida no meio rural no cenário nacional foi a I Conferência Nacional por uma Educação Básica do Campo em 1998, realizada na cidade Luziânia-GO. Dessa forma, julga-se pertinente ressaltar, ainda que sucintamente, os termos substituídos "Educação Rural” por "Educação no/do Campo".

Consoante às ideias de Fernandes, Cerioli e Caldart (2004) decidiu-se substituir a expressão "rural" por "campo", porquanto pretendia-se incluir no processo educativo uma reflexão a respeito do sentido atual do trabalho camponês e das lutas sociais e culturais que buscam viabilizar a sua sobrevivência por meio do trabalho, bem como a sua permanência e a conquista de um lugar próprio para aqueles que buscam retornar para o campo.

A respeito das preposições "no/do" em Educação no/do Campo, os pesquisadores Souza e Fernandes (2009) esclarecem que a educação "no campo" expressa um vínculo à localização do ensino no campo. Ou seja, ela deve possuir um vínculo espacial com o território e lugar do cam- 
ponês. Já o termo "do campo" em Educação "no/do Campo", refere-se à escola e à educação típicas, oriundas, da cultura dos sujeitos do campo, que valorize a identidade camponesa, congregando a pluralidade das ideias e concepções pedagógicas. A partir dessas considerações, optamos por utilizar no subtítulo deste trabalho a preposição "no", pois constatamos que a escola foco da pesquisa localiza-se no campo, contudo segue os preceitos da organização curricular e práticas das unidades escolares urbanas.

O projeto de educação do campo visa desenvolver uma escola que seja em sua completude do campo, uma escola não apenas desenvolvida no campo, mas também que assuma as práticas sociais do campo, dos camponeses e de quem more e tenha seus vínculos e raízes ligadas a um Brasil rural para a realização de atos educativos. Uma educação que é do campo e dos camponeses deve ser obrigatoriamente construída através da coletividade, e não como sempre foi e ainda vem sendo construída. $O$ sentido de educação para o campo reflete que a educação destinada para os sujeitos que moram no campo tenha sido uma educação construída por sujeitos de fora também, sem vínculos com o campo, e o que é mais grave, sem escutar o que os sujeitos do campo acreditam, ensejam, almejam e queiram no que se refere ao projeto de educação para seus filhos.

A II Conferência Nacional por uma Educação Básica do Campo em 2004, também realizada em Luziânia-GO, trouxe posições e reflexões de grande valia para a discussão e o desenvolvimento dessa modalidade. Na declaração final (Por uma Política Pública de Educação do Campo), traz indagações importantes como "Quem Somos", "O que Defendemos" e o "Que Queremos". Deixa claro, com efeito, quem são as pessoas, organizações e movimentos sociais que estão envolvidos na consolidação de um projeto de educação do campo, o que eles defendem e por que defendem, e finalmente, o que querem e o que acreditam que seja melhor para a educação do campo, lembrando que as transformações são vistas como direito dos camponeses e dever do estado.

Temos denunciado a grave situação vivida pelo povo brasileiro que vive no e do campo, e as consequências sociais e humanas de um modelo de desenvolvimento baseado na exclusão e na miséria da maioria. [...] Lutamos por um projeto de sociedade que seja justo, democrático e igualitário; que contemple um projeto de desenvolvimento sustentável do campo, que se contraponha ao latifúndio e ao agronegócio [...] (DECLARAÇÃO..., 2004, p. 1-2).

Nesse trecho da declaração fica claro o posicionamento e o protesto dos envolvidos na construção de um projeto de educação no/do campo. A promulgação da Constituição da República Federativa do Brasil em 1988 e a sanção da Lei de diretrizes e Bases da Educação Nacional (LDB), Lei 9.394/1996, também foram importantes e deram subsídios para a construção das Diretrizes Operacionais para a Educação Básica nas Escolas do Campo. Essas normativas legais foram instituídos pelo Conselho Nacional de Educação e pela Câmara de Educação Básica por meio da resolução CNE/CEB N ${ }^{\circ} 1$, de 3 de abril de 2002. Assim, reconheceu-se que as pessoas que vivem no campo têm direito a uma educação diferenciada em relação às que vivem na cidade (BRASIL, 2002).

A instituição das Diretrizes Operacionais para a Educação Básica nas Escolas do Campo pautou-se na legislação educacional atuante e visou atender parte das reivindicações dos movimentos sociais e daqueles que lutam por uma educação do campo. Um dos marcos dessas diretrizes foi o de reconhecer o modo próprio de vida social e a utilização do espaço do campo como fundamentais em sua diversidade, para a constituição da identidade da população rural e de sua inserção cidadã na definição dos rumos da sociedade brasileira, reconhecendo, assim, a identidade própria do camponês e o seu valor para a nação brasileira. 
Dentre elas o reconhecimento e a valorização da diversidade dos povos do campo, a for- mação diferenciada dos professores, a possibilidade de diferentes formas de organização da escola, a adequação dos conteúdos às peculiaridades locais, o uso de práticas peda- gógicas contextualizadas, a gestão democrática, a consideração os tempos pedagógicos diferenciados, a promoção, através da escola, do desenvolvimento sustentável e do acesso aos bens econômicos, sociais e culturais. (HENRIQUES et al., 2007, p. 17).

Portanto, essas diretrizes podem ser consideradas fruto de uma luta histórica de todos aqueles que reivindicaram (e ainda reivindicam) uma educação de qualidade para os sujeitos do campo.

A luta por uma educação do campo se faz principalmente por meio das exigências que cercam a constituição de políticas públicas que possam garantir esse direito, que afinal, é um direito de todos. Segundo Caldart (2002b), um dos principais objetivos a ser alcançado pelos movimentos sociais e por todos que lutam pela educação do campo é a conquista de políticas públicas que afirmem o direito do campo à educação. Souza (2011) ressalta ainda que os movimentos sociais de luta pela terra defendem a criação de políticas públicas que entendam o campo como espaço de vida, consolidando, dessa forma, a resistência contra o agronegócio e busca de uma consolidação de um território camponês.

De acordo com Nascimento (2004, p. 2):

A proposta de uma educação básica do campo sempre esteve ligada a um projeto popu- lar de educação e desenvolvimento para o país o que permite ampliar o leque de debates acerca dos problemas existentes no meio rural, ou seja, para que lutar por uma educação básica do campo se não há políticas públicas setoriais de combate à exclusão social, ao êxodo rural por parte dos jovens, ao analfabetismo funcional, à agricultura familiar etc.

Nessa perspectiva deve-se ressaltar que a educação do campo se enquadra em uma categoria maior, a da educação popular, tão defendida pelo educador Paulo Freire. Nascimento (2004) esclarece que não há sentido em lutar por uma educação básica do campo de qualidade e que atenda às demandas dos sujeitos do campo se ela não estiver vinculada a políticas públicas que, além da educação, visem atender ao contexto social e econômico que regem o campo brasileiro.

Segundo Freire (1981, p. 69), "a ação cultural para a libertação e a revolução cultural implicam na comunhão entre os líderes e as massas populares, como sujeitos da transformação da realidade". Freire acredita na participação popular para a libertação e revolução cultural, na qual a educação é considerada como ponto chave, como mecanismo da massa para compreensão da realidade e das condições que a encaminham, consequentemente, para a libertação.

$\mathrm{Na}$ opinião de Nascimento (2004), as escolas do campo mais do que deter uma perspectiva pedagógica que se faz a partir da comunidade, deveriam ser consideradas como um espaço de reconstrução da memória coletiva e histórica de toda a comunidade. Para isso, segundo o autor, é mister assumir posturas pedagógicas que venham enriquecer a possibilidade do diálogo e a implantação de muitas educações, visto que o Brasil é um país pluriétnico e pluricultural e uma dessas pedagogias é a educação popular e libertadora.

Para Benjamin e Caldart (2000, p. 37) "somente as escolas construídas política e pedagogicamente pelos sujeitos do campo, conseguem ter o jeito do campo". Nesse diapasão, Souza (2011) destaca que não é possível a execução de um Projeto Político Pedagógico (PPP) ligado à educação do campo realizado apenas na perspectiva de uma transposição da escola urbana para o campo. Espera-se da escola um comprometimento com esse lugar de produção social. Para isso, torna-se fundamental as políticas educacionais e que entre elas o seu PPP esteja vinculado com o projeto de educação dos sujeitos no/do campo. Segundo Arroyo (2007, p. 163): 
Uma das marcas de especificidades da formação: entender a força que o território, a terra, o lugar tem na formação social, política, cultural, identitária dos povos do campo. Sem as matrizes que se formam sem entender a terra, o território e o lugar como matrizes formadoras, não somos capazes de tornar a escola um lugar de formação.

Portanto, dos professores se espera engajamento político e social, que eles lutem contras as barreiras pedagógicas, estruturais e políticas para que, de fato, considere-se o entendimento da realidade do campo como caminho para o desenvolvimento da práxis educacional em prol da transformação social.

Depara-se com um cenário no qual a escola no campo é da cidade, ou no qual os moradores do campo são assumidos, mesmo residindo no campo, como alunos de escolas da cidade. Escolas da cidade, pois seu projeto pedagógico não está inserido como o projeto que vise atender aos anseios camponeses e porque majoritariamente em seu corpo funcional as pessoas vivem na cidade e vão ao campo para trabalhar. Em decorrência desses fatos, não há um comprometimento com a manutenção de uma escola do campo no campo. Ressalte-se que não há problemas no que concerne à atuação de profissionais da educação, formação num contexto urbano, mediando uma educação no/do campo. Há, sim, problemas quando tais profissionais não buscam fazer uma educação a partir do campo, quer dizer, da realidade do campo, a partir da realidade social no qual aqueles indivíduos se encontram. E é claro, exige-se do governo incentivo à formação continuada desses profissionais e o oferecimento de cursos que sejam voltados para o aperfeiçoamento da atuação docente no campo. Assim, é premente que a escola não seja somente sobre o campo ou para o campo, mas, além disso, seja do campo.

A discussão a respeito da educação no/do campo não se limita apenas ao que foi discutido aqui. Afinal, pelo fato de ser assumida com limitações e imperar no esquecimento por parte do poder público, os movimentos sociais e os sujeitos do campo passaram a cobrar, reivindicar os seus direitos de forma a superar a concepção simplista de educação, ao remeter-se aos sujeitos do campo, como por exemplo, denominações como: "a escolinha rural, da roça, qualquer coisa serve ou para mexer com a enxada não precisa de muitas letras". (NASCIMENTO, 2003, p. 5).

\section{3 | Vida no campo no Brasil: alguns indicadores}

Os sujeitos do campo são todos os indivíduos que estão vinculados material ou imaterialmente com o campo, por exemplo: camponeses, quilombolas, indígenas, assentados. A Política de Saúde para a População do Campo, com objetivo de conceituar a população do campo, destacou os seguintes seguimentos:

[...] os segmentos populacionais de agricultores (as) familiares, trabalhadores (as) rurais assalariados (as) e aqueles (as) em regime de trabalho temporário, os (as) trabalhadores (as) rurais assentados, os (as) trabalhadores (as) rurais que não têm acesso a terra - fa- mílias de trabalhadores (as) rurais de assentamentos e acampamentos rurais, populações que residem em comunidades remanescentes de quilombos, em reservas extrativistas, em vilas, povoados, população ribeirinha, populações atingidas por barragens, comunidades tradicionais e trabalhadores que moram na periferia das cidades e que trabalham no cam- po. (BRASIL, 2004, p. 3).

Atualmente, $15,6 \%$ da população brasileira, segundo o censo demográfico realizado pelo Instituto Brasileiro de Geografia e Estatística (IBGE), vive em área rural e esse número, se tiver a mesma tendência dos últimos censos, tenderá a diminuir (INSTITUTO BRASILEIRO DE GEO- 
GRAFIA E ESTATÍSTICA, 2011). Então, por que discutir acerca de uma população em decadência e que investimentos devem ser feitos para atender uma população que é minoria no país? Não seria um processo fadado à dissipação? Bom, esses dados são um fato, não se pode negar, porém, é necessário entender o contexto histórico no qual tal fato se deu para que conclusões possam ser construídas. Em um curto intervalo de tempo, menos de 50 anos, a população brasileira passou de majoritariamente rural para urbana, influenciada globalmente pelos processos de industrialização e urbanização e a partir da Segunda Guerra, influenciada pela revolução verde, porquanto se passou a produzir mais alimentos. Acerca desses processos deparou-se com os principais eventos que influenciaram e influenciam a angústia do movimento camponês atual.

Segundo Woortmann e Woortmann (1997, p. 25, grifo do autor), "o espaço camponês encolhe significativamente, mas as soltas continuam a povoar a memória, como condição de ser liberto". Daí compreende-se que, apesar de minoria, existe uma maioria nas pequenas, grandes e médias cidades que mantém um vínculo com a simbologia do campo. Esses sujeitos perderam seu lugar, mas mantêm materializado e eternizado em suas memórias e muitos tentam voltar para o campo através dos movimentos sociais organizados, que de um lado lutam por melhorias da qualidade de vida no campo e, por outro lado, tentam reinserir, reincluir o homem do campo sem campo agregado na cidade. Por isso, a educação do campo não se sustenta só no âmbito escolar, na educação formal, ela tem que ser vinculada com a educação não formal, no qual os movimentos sociais fazem parte. Entender esses processos é fundamental para a valorização da educação do campo e de sua identidade.

Segundo Nascimento (2003), de acordo com os dados do IBGE, a população rural é vista como uma população fadada ao esquecimento. Para ele o atual sistema vigente gerou uma série de anomalias, sobretudo com a concentração de terra e renda, a concentração urbana, o desemprego e o aumento da violência, além de determinar o modelo urbano como o modelo a ser seguido em detrimento do rural. Dessa forma, segundo o mesmo autor, devido ao avanço do capitalismo no campo, criaram-se três problemas para os camponeses: primeiro, um desenvolvimento desigual; segundo, um processo excludente que resultou no êxodo rural; e, por último, um modelo de agricultura que produz relações sociais ora atrasadas ora modernas. Ou seja, o sistema capitalista acabou gerando sérios problemas para a existência do camponês e para aqueles que resistem e não se adaptam ao modelo implantado.

Nesse sentido, Santos (2000) afirma que em nenhum outro país foi contemporâneo e concomitante o processo de descidadania, que vale citar aqui a desruralização, as migrações brutais desenraizadoras, a urbanização galopante e concentradora, a degradação das escolas e uma série de suspensão de direitos e a imposição de uma filosofia de vida que privilegia os meios materiais, instalando o egoísmo com lei superior. A terminologia cidadão foi substituída nesse caso por consumidor que, para Milton Santos, aceita ser chamado de usuário. Dessa forma, houve uma desconsideração dos direitos básicos dos seres humanos, dos cidadãos, o que passou a valer foi a sinfonia do consumo e de quem pode consumir.

A cidadania que falta não é apenas urbana, mas também e sobretudo a cidadania rural, para o qual contribuem conjuntamente o mercado e o Estado. $O$ homem do campo bra- sileiro, em sua grande maioria, está desarmado diante de uma economia cada vez mais modernizada, concentrada e desalmada, incapaz de se premunir contra as vacilações da natureza, de se armar para acompanhar os progressos técnicos e de se defender contra as oscilações dos preços externos e internos e a ganância dos intermediários, esse homem do campo é menos titular de direitos que a maioria dos homens da cidade, já que os serviços essenciais the são negados sob a desculpa da carência de recursos para lhe fazer chegar saúde e educação, água e eletricidade, para não falar de tantos outros serviços essenciais. (SANTOS, 2000, p. 28-29). 
Infelizmente, Milton Santos descreve uma realidade latente na sociedade brasileira em que, além de muitos brasileiros não possuírem status de cidadão, o homem do campo amarga a triste realidade de ser menos cidadão do que os demais.

Segundo o Atlas do Espaço Rural Brasileiro, realizado pelo Instituto Brasileiro de Geografia e Estatística (apud NASCIMENTO; SILVA, 2011), os resultados apresentados pelo Censo Agropecuário de 2006 mostram que existe uma situação de consolidação de regulação fundiária, apesar da pequena presença de estabelecimentos, mesmo em regiões de fronteira agrícola. Ou seja, esses dados revelam que existe uma grande concentração de terra no país, mesmo em áreas que são de fronteira agrícola, de forma que $84,4 \%$ dos estabelecimentos agropecuários do país (4,4 milhões), estabelecimentos esses destinados aos camponeses ou agricultor familiar, representam apenas $24,3 \%$ (80 milhões de hectares) da área total dos estabelecimentos agropecuários. Estes ficam apenas com 18,3 hectares, em média, por estabelecimento, enquanto os outros grupos ficaram em média com 330 hectares.

No que tange à instrução dos proprietários ocupantes dos estabelecimentos rurais, os dados analisados pelo Atlas através do Censo Agropecuário de 2006, são alarmantes, e denunciam a situação da educação no campo brasileiro. Os dados mostram que $80 \%$ dos produtores entrevistados possuem baixa escolaridade. Ou seja, a maioria não sabia ler e escrever, 39\% não tinham frequentado a escola e $43 \%$ não possuíam o ensino fundamental completo. Esse dado, segundo o Atlas, foi confirmado na Pesquisa Nacional por Amostra de Domicílios (PNAD) em 2007, na qual $40 \%$ dos brasileiros analfabetos, que totalizam 9,6 milhões de pessoas entre 15 e 60 anos de idade, vivem no campo. Ainda analisando esse dado, um dos fatores que mais preocupa é o número de mulheres analfabetas que responderam à entrevista, o número chega a $45,7 \%$. De maneira preocupante também, os homens que são analfabetos corresponderam a 38,1\% (NASCIMENTO; SILVA, 2011).

Outros níveis de escolaridade no campo se apresentam quase que inexpressivos: 8\% para o ensino fundamental completo; $7 \%$ para técnico agrícola ou nível médio completo e apenas 3\% com nível superior. Ainda, ao se analisar a distribuição espacial do analfabetismo, os dados revelaram que as Regiões Norte e Nordeste possuem maior número de analfabetos em comparação com as demais (BRASIL, 2012).

As informações e as indagações a respeito da vida no campo não se limitam ao exposto. Os dados aqui apresentados possuem o objetivo de suscitar reflexões atinentes à realidade do campo e incentivar o leitor à procura de mais informações, estudos e dados que possam desmitificar o espaço rural brasileiro e perceber o panorama da educação do/no campo. A seguir, apresentar-se os resultados da pesquisa empreendida com os discentes e pais no âmbito da educação do/no campo, em uma escola localizada na Região Administrativa de Planaltina (DF).

\section{4 | Sujeitos pesquisados e indicadores do lugar em que vivem}

Foram entrevistados, ao todo, 42 alunos do $3^{\circ}, 4^{\circ}$ e $5^{\circ}$ anos do ensino fundamental - anos iniciais ${ }^{1}$ que estudavam no período matutino de uma escola localizada no campo, em Planaltina, Distrito Federal² (Figura 1).

Segundo o censo escolar realizado pelo Programa Nacional de Alimentação Escolar - Pnae, no ano de 2012, período em que foi realizada esta pesquisa, o número de alunos era de 79 , sen-

\footnotetext{
${ }^{1}$ Essa mesma escola também ofertava e ainda oferta vagas para a Pré-escola.

${ }^{2}$ Entendemos que escolas do campo "são aquelas que têm sua sede no espaço geográfico classificado pelo IBGE como rural, assim como as identificadas com o campo, mesmo tendo sua sede em áreas consideradas urbanas. Essas últimas são assim consideradas porque atendem a populações de municípios cuja produção econômica, social e cultura está majoritariamente vinculada ao campo (HENRIQUES et al., 2007).
} 
do que $61 \%$ deles pertenciam ao ensino fundamental - anos iniciais. Dados referentes ao ano de 2014 indicam-nos um crescimento de $26,5 \%$ referente ao ano de 2012, agora com $79 \%$ dos alunos pertencentes ao ensino fundamental - anos iniciais (FNDE, 2013).

A média de idade dos alunos do $3^{\circ}$ ano era de 8,7 anos variando de alunos com 8 a 13 anos. A média do $4^{\circ}$ ano era de 10,1, com variação de alunos com 9 a 12 anos. O 5ํano com média de 11,2 , com variação de 10 a 15 anos. Nesse sentido, cabe registrar, segundo as informações coletadas, que expressiva parte dos alunos se encontra em distorção de idade série, ou seja, uma significativa parte está matriculada em turmas que, em relação às suas idades, estão atrasadas no seu processo de aprendizagem escolar. $O$ índice de distorção em idade por série é motivo de preocupação, o que requer providências tanto da instituição escolar, como de políticas públicas que assegurem o direito que a criança tem de aprender na idade certa.

Figura 1 - Vista da escola pesquisada



Fonte: Elaborado pelos autores

Entre os sujeitos dessa pesquisa, dezesseis $(38 \%)$ eram do sexo feminino e vinte e seis $(62 \%)$ do sexo masculino. Entre eles, vinte $(47,5 \%)$ estudantes se declararam brancas, vinte $(47,5 \%)$ pardas, e apenas duas $(5 \%)$ se declararam negras ou indígenas.

Todos revelaram que tinham residência na Região Administrativa de Planaltina-DF ou em Planaltina-GO, compreendendo as comunidades denominadas Sarandi, Assentamento Mangabeira, Brotão, Embrapa núcleo rural e Grotão. 
A respeito da moradia, trinta e cinco (83\%) alunos informaram que moravam em casas e sete (17\%) alegaram que moravam em barracos, alternativas como apartamento, cortiço e outros não foram observadas. A respeito da posse dessas moradias, vinte e oito (67\%) dos discentes declararam que residem em casa própria, quatro $(9,5 \%)$ alugada, dois (5\%) cedida, um (2\%) invadida e setes 16,5\% não souberam informar. Segundo relatos dos estudantes, a média apresentada de pessoas por habitação foi de 4,9 pessoas. Média superior a nacional, que é de 3,1 habitantes por domicílio, segundo pesquisa realizada pelo Programa de Amostra em Domicílio (PNAD) do IBGE (2008).

Sobre o meio de transporte, $41 \%$ têm como meio principal o transporte público, $37 \%$ o carro, $16 \%$ a moto, $4 \%$ a bicicleta e $2 \%$ a carroça. A maioria depende do ônibus para a locomoção de suas casas para a escola. Observou-se que parte expressiva dessas famílias é dependente do transporte público e não possui um veículo próprio para se locomover, dificultando mais ainda a vida no campo, visto que os transportes públicos em geral não apresentam boas condições e horários flexíveis para transportar essa população.

Sobre a religião, $51 \%$ se declararam evangélicos, 37\% católicos, 2,5\% protestante, 2,5\% espírita e $7 \%$ declararam não possuir religião. Para $86 \%$ dos alunos há concordância com os preceitos de sua religião, do quais 58,5\% praticam tudo, 33,5\% praticam quase tudo e $8 \%$ não pratica nada. Apenas 14\% discordam do que prega sua religião, porém 50\% desses, apesar de discordarem, alegam que praticam tudo. Percebeu-se que a maioria dos alunos possui um preceito religioso, no qual a religião evangélica se destaca por atrair maior número de religiosos. Observou-se que a maioria pratica os preceitos de sua religião mesmo discordando de alguns pontos.

Das crianças, 98\% veem importância em preservar a natureza. Entre as justificativas estão a importância da natureza para os seres humanos; a beleza da natureza; a necessidade de preservar os rios para a água não acabar; a natureza como a casa dos animais e a necessidade de cuidar deles. Apelos como não poluir, não desmatar, não jogar lixo, não queimar e não derrubar, Porque sem a natureza nós não vivemos, respiramos e tudo mais foram justificativas encontrados nas respostas. Em uma das respostas ficou claro a dependência da natureza para o plantio que deve ser um meio de subsistência da família do aluno: Eu planto com meu vovô.

Talvez o contato permanente com o ambiente natural faça com que maioria dessas crianças saiba preservar e valorizar o meio ambiente, já que também o seu lar se encontra no meio da natureza, e muitas famílias não tiram o sustento de lá, mantém o pequeno cultivo de plantas e animais que acabam suplementando a alimentação e renda da família. Essas concepções podem estar ligadas às ideias que os próprios pais desses estudantes possuem da natureza e acabam de uma maneira direta ou indiretamente transmitindo aos seus filhos.

A respeito das novas tecnologias, $83 \%$ dos alunos entrevistados alegaram que sabem manusear o computador e $17 \%$ alegam que não sabem manusear esse equipamento. Dentre os alunos, $73 \%$ afirmaram que utilizam o computador em casa, $10 \%$ em uma Lan House ${ }^{3}, 6 \%$ na escola e o restante responderam no trabalho ou no vizinho. Sobre a internet, $48 \%$ dos alunos alegam que possuíam acesso a internet em casa, 40\% não possuíam e 12\% não responderam. Perguntados como se mantêm informados, $36 \%$ alegaram que se mantêm informados por meio da TV, $26 \%$ por meio do jornal, $10 \%$ da internet, $10 \%$ pelo amigo e $8 \%$ por meio do rádio, $10 \%$ dos entrevistados não responderam às questões.

Notou-se que boa parte dos alunos alegou saber manusear o computador. O número de casas que possui um computador foi bastante considerável. Apesar do fato de o acesso à internet ser um pouco mais tímido, isso é um indicador positivo no campo, viabilizando assim, a inclusão digital desses alunos, contanto que Ihes seja possibilitado educação para tal. A escola, pelo visto,

\footnotetext{
3 "A Lan House é um local aberto ao público em horas predefinidas como qualquer outro estabelecimento comercial, onde as pessoas pagam para utilizar um computador ligado em rede e com acesso à Internet [...]" (MATEUS, 2006, p. 6, grifo nosso).
} 
deixa muito a desejar enquanto agente que deveria viabilizar a inclusão digital desses alunos.

Acerca da leitura, 93\% dos alunos afirmam que gostam de ler, e apenas 7\% afirmam que não gostam de ler; 95\% alegaram gostar de estudar e 5\% a legaram não gostar de estudar. Excetuando-se os livros escolares, $28 \%$ dos alunos afirmaram que leem mais de 8 livros no ano, 12\% de 6 a 8 livros 26\% de 3 a 5 livros, 24\% no máximo dois livros e 10\% nenhum livro. Entre as temáticas foram citadas: Aventura, História de Jesus Cristo, folclore, futebol, conto de fadas, cavalos, ciências, corrida, histórias em quadrinhos e gibis. Clássicos - Os três porquinhos, Rapunzel, Pica Pau e o autor Monteiro Lobato - também foi citado.

Os indicadores encontrados na escola são positivos, visto que a maioria gosta de ler e estudar, em que 54\% leem pelo menos de 3 a 5 livros por ano, número que poderia ser maior, mas devido à série e às dificuldades de leitura e escrita que alguns dos professores alegaram constituem um grande problema na escola, esses indicadores são positivos. As obras e os temas indicam o interesse desses alunos pela literatura infantil.

Freire (2001, p. 267) destaca o papel da leitura e da escola no despertar dessa atividade, para ele:

Se nossas escolas, desde a mais tenra idade de seus alunos se entregassem ao trabalho de estimular neles o gosto da leitura e o da escrita, gosto que continuasse a ser estimulado durante todo o tempo de sua escolaridade, haveria possivelmente um número bastante menor de pós-graduandos falando de sua insegurança ou de sua incapacidade de escrever. Se estudar, para nós, não fosse quase sempre um fardo, se ler não fosse uma obrigação amarga a cumprir, se, pelo contrário, estudar e ler fossem fontes de alegria e de prazer, de que resulta também o indispensável conhecimento com que nos movemos melhor no mun- do, teríamos índices melhor reveladores da qualidade de nossa educação.

Entre as disciplinas, Matemática (30\%) e Educação Física (30\%) são as matérias preferidas dos alunos, seguida de Artes (15\%), Português (15\%), Ciências Sociais (7\%) e Religião (3\%). Esse indicador provavelmente está vinculado com a metodologia de ensino-aprendizagem promovida pelos professores, além da intimidade em lidar com esses conhecimentos tanto do professor quanto do aluno.

Perguntados se utilizam os saberes aprendidos na escola em seu dia a dia, a maioria respondeu que sim, que ajuda na leitura de informações e livros, no estudo de matemática, escutando e obedecendo a seus pais no estudo em casa e para ajudar as pessoas. O futebol e o jogo da queimada foram as atividades esportivas mais mencionadas quando foi perguntado aos alunos sobre a prática e a frequência da prática de esporte. Foram mencionados também vôlei, caminhada e corrida, variando a frequência de prática dessas atividades de todos os dias a uma vez na semana. Notou-se que a prática do esporte está vinculada com o lúdico e com a brincadeira, o que faz os alunos misturarem a prática de esporte com a diversão.

Dentre as profissões preferidas foram citadas advogado/juíz, Forças Armadas (Exército e Aeronáutica), modelo, veterinário(a), bombeiro, cantora, estilista, médico (a), jogador de futebol, cabeleireira, e professora. Policial e bombeiro foram as profissões mais citadas entre os meninos e estilista e médica, entre as meninas. Tirando veterinário e até mesmo professor, todas as outras profissões citadas não visam, de acordo com os ditames da sociedade, à manutenção desses alunos no campo. O que mostra que o campo pode perder boa parte desses sujeitos se tais desejos forem concretizados.

Das crianças entrevistadas, 95\% afirmam que gostam de brincar, cabendo investigar os 5\% que declararam não gostar, pois o brincar é algo natural da infância. Perguntados sobre as brin- 
cadeiras preferidas entre as meninas foram citadas: andar de bicicleta, brincar de boneca, bola, escolinha, pique-pega, pique-esconde, pique-escola, fazer bolo de terra, roda-roda, queimada, pipa, bola, amarelinha, pular corda e brincar com os animais. Já os meninos citaram: futebol, videogame, andar de bicicleta, pique-esconde, pique-pega, subir na árvore, carrinho de controle remoto, lutinha, queimada e vôlei. Brincar com bonecas foi quase unanimidade entre as respostas das meninas, assim como, futebol foi entre os meninos. Queimada, andar de bicicleta, pique-pega e pique-esconde foram brincadeiras em comum citadas.

Esses relatos revelam que muitas brincadeiras no campo ainda estão preservadas, e apesar de se vivenciar a era da tecnologia e informática, detectou-se que a tecnologia pouco influenciou sobre as brincadeiras praticadas por meninos e meninas dessa escola no campo. Esses relatos podem indicar ainda as condições das famílias em adquirirem brinquedos e equipamentos mais aperfeiçoados para seus filhos.

Um dos dados preocupantes constatados concerne à ocorrência do bullying 4 na escola. Segundo Fante (2005), bullying são atitudes que se caracterizam pela repetição e pelo desequilíbrio de poder e uso de violência, criando, assim, um subconjunto de comportamentos agressivos que envolvem exclusões, discriminações, insultos e assédios de todo gênero que muitas vezes têm a finalidade de maltratar, intimidar e causar sentimentos de angústia e sofrimento.

Dos alunos, $60 \%$ alegaram que sofreram discriminação ou bullying na escola e $40 \%$ alegaram que nunca sofreram. Porém, $86 \%$ dos alunos afirmaram que já presenciaram algum tipo de discriminação ou bullying com seus colegas na escola. As discriminações sofridas ou presenciadas são diversificadas, envolvendo cor, tamanho, peso e estética. Os alunos relatam que acabam presenciando xingamentos e até mesmo agressões. Entre os apelidos encontramos: "Neguinho", "Zê da Viola", "Maranhão", "Gordo", "Magro", "Branquelo(a)", "Beisão", "Cego", "Quatro Olhos", "Pequinês" entre outros (sic!).

Observa-se que muitos desses preconceitos estão vinculados com características físicas e necessidades biológicas dos alunos, o que não deixam de ser padrões impostos pela sociedade. Porém, muito deles referem-se a estereótipos altamente marcados e reproduzidos pela sociedade brasileira, o racismo e o preconceito de localização, como é o caso de "Maranhão" e também de "Zé da Viola". O primeiro fazendo menção a um dos estados mais pobres do Brasil, a questão do mesmo fazer parte da região Nordeste também pode ser mencionada, visto o grande preconceito com essa população. O último fazendo menção, de forma generalizada, ao homem do campo, visto que, a viola é um elemento forte da identidade e da cultura camponesa.

Esses fatores, apesar de não serem exclusivos do campo, indicam que existem muitos preconceitos contra os alunos do campo. Muitas vezes existe um autopreconceito, no sentido de se achar e sentir como uma figura negativa, muitas vezes incorporada pela convivência de algum grupo a que pertence ou pessoa do qual conhece ou até mesmo por uma concepção atribuída por uma pessoa não pertencente ao grupo. O convívio dos alunos com pessoas que fazem apologia à discriminação de todos os gêneros acaba influenciando posturas que esses tomam perante a sala de aula e seus colegas às vezes pensam que a maldade está no aluno que indica e discrimina e se esquece de que existe um sistema social que induz a essas atitudes.

Foram enviados para os pais, ao todo, 42 questionários, porém apenas 19 retornaram respondidos. Acredita-se que os motivos para esse fato sejam variados, pois muitos trabalham e acredita-se que não tiveram o tempo hábil para responder ao questionário, ou ainda, é provavel (sem levantar nada concreto), que muitos sejam analfabetos ou tenham dificuldades em leitura e escrita. Dessa forma, os dados obtidos foram analisados de maneira predominantemente qualitativa.

Segundo os dados coletados, cada família possuía em média 2,4 filhos que frequentavam a

\footnotetext{
4 "Termo da língua inglesa, deriva do substantivo bully, para o qual o dicionário Oxford traz a seguinte definição: "a person who uses their strength or power to frighten or hurt weaker people: the school bully" (uma pessoa que utiliza força ou poder próprios a fim de amedrontar ou ferir pessoas mais fracas: o bully escolar)" (SANTOS, 2008, p. 1, grifos da autora).
} 
escola. Notou-se que este é um número elevado de filhos na escola, o que pode desequilibrar as finanças da família, mormente no começo do ano, quando há a compra de materiais escolares. Ainda segundo os pais, a escola é a mais próxima ficando em média 2,6 km de distância da residência dos alunos.

Acerca do nível de escolaridade, dos pais que responderam $68 \%$ declararam que possuíam ensino fundamental incompleto, $21,5 \%$ analfabetos, $10,5 \%$ ensino médio completo. As mães: $47 \%$ ensino fundamental incompleto, $21 \%$ com ensino médio completo, $10,5 \%$ analfabetas, $16 \%$ com ensino fundamental completo, 5,5\% com ensino superior incompleto. Caseiro, encarregado de depósito, doméstico, serviços gerais, operário do campo, auxiliar de produção, servente, vidraceiro, carpinteiro foram as profissões/afazeres citados pelos pais. Já entre as mães foram citados: empregada doméstica, dona de casa, diarista, agricultora e serviços gerais. Chamou atenção em um questionário que foi preenchido no espaço que se referia às informações do pai: "não tem pai", deixando explícitas as vulnerabilidades sociais que alguns alunos possuem.

Sobre a renda familiar, $63 \%$ dos pais afirmaram que os valores são de até um salário mínimo; $16 \%$ de 2 a 5 salários mínimos; $10,5 \%$ de 1 a 2 salários mínimos e 10,5\% nenhuma renda. A maioria das casas, segundo os pais, não possuía pessoas com carteira assinada, e quando tal fato ocorria esse se concentrava com o pai.

Percebeu-se que o nível de escolaridade e de renda tanto dos pais quanto das mães são muito baixos, com destaque ao ensino fundamental incompleto. Entre os pais, o índice de analfabetismo apresentado é de mais de $20 \%$. A renda é de até 1 salário mínimo. Apesar disso, tudo indica que o homem, na figura do pai, ainda apresenta destaque em relação à esposa, quando se leva em consideração a incidência de carteira assinada. Esses dados refletem um passado recente no qual o sujeito do campo foi considerado um ser que não necessitava de estudo, ressalva quando o governo oferecia apenas o ensino fundamental anos iniciais no campo que por si só não adiantava muita coisa - escola no campo e visão da cidade.

Esses dados refletem também as condições de trabalho, todos sem necessidade de muita especialização profissional, todos eles ocupando serviços e empregos do circuito inferior da economia. Como observa Santos (2012), essas atividades são compostas por formas de atividades não-modernas e de pequeno porte que implica em intensiva mão de obra e horas trabalhadas. Ainda segundo ele, essas atividades estão vinculadas com as condições de vida da população de baixo poder aquisitivo. Isso demonstra, assim, mais uma forma de degradação das condições de vida das pessoas que moram no campo.

Outro fator preocupante a ser ressaltado é a questão que a maioria desses sujeitos não tira mais o próprio sustento da terra em que vivem, exceto alguns que vivem de forma assalariada no campo. Mesmo assim, observou-se um desenraizamento das relações de trabalho com a terra, o que Oliveira (1991) vem chamando de destruição do trabalho familiar camponês pelo capital.

Ainda segundo Woortmann e Woortmann (1997), o processo de trabalho, além de produzir alimentos, produz relações sociais, na medida em que a maneira de trabalhar é um modo de produzir pessoas. Ficando, assim, o trabalho e reprodução do estilo de vida e cultura dessas pessoas comprometidas às futuras gerações.

De acordo com o estudo foi constatado que pelo menos uma vez ao mês as famílias costumam ir à cidade, perímetro urbano. A visita semanalmente foi mais citada entre os entrevistados, há casos de pessoas que vão todos os dias à cidade, o que pode estar relacionado com o trabalho e com a dependência de realizar serviços na cidade. A maioria declarou que mora em propriedades rurais de até 10 hectares. Observou-se que muitos não possuem propriedade e moram como assentados, caseiros e em terrenos cedidos ou invadidos, caracterizando-se assim como pequenos produtores e assalariados rurais ou urbanos.

Algumas perguntas foram destinadas exclusivamente para as pessoas que moram na zona rural. Foi perguntado quantas culturas eram cultivadas na propriedade, em que se observou que 
muitos, apesar de morar na zona rural, não cultivam nenhuma cultura. Entre os que cultivam, constatou-se que o sistema adotado foi o de policultura. Entre as culturas citadas estavam: alface, mostarda, cebola, couve, "folhagem", milho, feijão, mandioca, batata-doce, abóbora e o cheiro verde.

Todos os agricultores alegaram que o cultivado em sua propriedade é para subsistência e apenas $23 \%$ deles vendem o excedente para o mercado. Nenhum agricultor possui funcionários e alguns recebem ajuda dos parentes em sua propriedade. Todos os entrevistados criam animais em sua propriedade; entre os citados, encontram-se: galinha, porco, preá, porquinho da índia, gado, cavalos, aves, cachorro. Percebe-se que são práticas e culturas típicas camponesas, apesar do capitalismo estar corroendo essa cultura, conforme estamos vendo até o momento.

Acerca do plantio, $46 \%$ informaram que o tipo de plantio realizado na propriedade é tanto direto como indireto, 39\% de forma direta e 15\% de forma indireta; $62 \%$ dos agricultores afirmaram que não realizam rotação de culturas em sua propriedade, $38 \%$ afirmara que a realizam. $\mathrm{Ne}$ nhum agricultor mencionou que utilizava agrotóxicos ("defensivos agrícolas") em sua propriedade. A maioria relatou que utiliza insumos orgânicos e realizam o plantio de forma manual, sendo que a técnica de aração também foi citada. Perguntados se acreditam que o calendário escolar seja adequado às necessidades da família, 90\% responderam que sim.

Notou-se que muitos não cultivam alguma cultura na terra, relação que pode ter sido dada pelo efeito do capitalismo na destruição do trabalho camponês. A maioria que cultiva algo é destinada à subsistência, o que justifica a cultura variada. Já a respeito dos animais, todos criam algum tipo: a galinha e o porco foram citados e podem ser destacados como animais típicos das pequenas propriedades e da cultura camponesa. Observou-se que as práticas adotadas na agriculta são bastante simples, o plantio direto, por exemplo, é uma técnica simples que causa pouco impacto no solo em comparação com o plantio indireto, apesar de a maioria não usar a rotação de cultura.

O que chamou atenção, realmente, foi o fato de nenhum dos pesquisados não lançarem mão do uso de agrotóxicos em suas propriedades e fazerem o plantio de forma manual. Os insumos orgânicos foram citados com fertilizantes para o solo, mais uma característica que caracteriza a cultura camponesa, apesar de muitos estarem submetidos à condição de assalariados. Sobre o calendário escolar, quase todos responderam que ele está adequado com o cotidiano da família. Talvez as relações de cunho urbano estejam tão penetradas no ideário desses sujeitos que de fato não se necessite adaptar o calendário escolar, exceto se houver rupturas necessárias, pois a lógica capitalista e urbanoide não se adequaram ao estilo de vida dos sujeitos do campo.

Perguntados se acreditam que os fatores religiosos e os elementos místicos da natureza afetam na produção agrícola, as opiniões se dividiram. Entre as opiniões encontramos: Não, por que muita gente acha que ela se torna vingativa por causa do jeito que nós tratamos a natureza, não, acredito no cuidado em manejar a terra e no carinho que se tem com o trabalho que se faz. Porém muitos acreditam, fato que podemos observar nos seguintes comentários: Sim, por que ela é de Deus; Sim, a chuva, o sol muito quente acaba com tudo, Temos que ter fé, em tudo que plantamos para obter um bom plantio, Tem que plantar na época de lua nova; Sim, se você agredir a natureza ela não produz o fruto sadio. Houve casos nos quais a pessoa descreveu que não soube explicar sim ou não.

A maioria acredita que a natureza é vingativa. Entre os comentários encontramos: se agredir a natureza ela não produz como tem que produzir os frutos da terra; porque os seres humanos, faz muita derrubada na mata; sim, pois se há desmatamento e poluição nas águas o solo que tem aspecto será fraco, sim, porque o homem faz muita derrubada e prejudica a natureza; sim quando cai chuva de gelo destrói.

A maioria também disse que procura causar menor impacto possível no plantio: sim, preocupo 
muito, tem que evitar alguns impacto; sim procuro separa o lixo comum orgânico que pode ser usado como adubo e o lixo comum pode ser reciclado; sim usamos orgânicos para não afetar o solo. Ainda segundo um respondente, se desmatar ou poluir as nascentes se secam, causa chuva ácida, terremotos, tempestades...

Percebeu-se que, apesar de alguns se mostrarem contra ou até mesmo duvidosos sobre o poder da natureza e divindades que a controlam, a maioria acredita que os fatores religiosos e místicos da natureza acabam influenciando na agricultura, fator pelo qual muitos fazem seus rituais, oram e seguem indicadores da natureza. Além disso, procuram contrariar ao mínimo as forças da natureza e de Deus para que tudo dê certo na colheita. Pois a maioria acredita que a natureza seja vingativa na forma que tudo que se faz mal para ela acaba retornando e prejudicando a agricultura e a vida das pessoas que a agrediu. Dessa forma, muitos procuram causar menor impacto possível no plantio. Concepção semelhante encontra-se em pesquisa realizada por Woortmann e Woortmann (1997, p. 171) com sujeitos do campo do estado de Sergipe: "se a seca é castigo de Deus aos homens que infringiram o ordenamento moral por Ele determinado, ela é também parte da natureza por Ele ordenada".

As famílias que cultivam alguma cultura atribuem a sua importância para subsistência da família, para uma alimentação saudável e até mesmo como fonte de renda. Os comentários foram os seguintes: para o sustento proprio com verduras, frutas, folhagem, sem agrotoxo quimico; que para consumir e vender é necessário colher; no sustento proprio; a importância é que através da colheita que trás o alimento para a mesa; a importância, é plantar e colher o alimento para alimentar os filhos, sustento próprio, a importância de uma alimentação de qualidade, a sustentabilidade da propria família. Esses comentários mostram a importância dada às culturas. Mesmo em pequena quantidade elas acabam suplementando a alimentação da família e até mesmo a renda. Eles ligam ainda com a importância de alimentar os filhos, a sustentabilidade da família e uma alimentação de melhor qualidade já que eles não usam agrotóxico.

As opiniões são diversificadas também quando foi perguntado aos pais a idade que eles acham correto o início do trabalho por parte de seus filhos. Independente da idade mencionada, observou-se que o trabalho é dotado de grande valor para dignidade humana e para o sucesso na vida, a educação é bastante citada, dessa forma, se liga a um bom emprego e o sucesso na vida profissional com o estudo.

Os comentários a seguir foram de grande valia para essa reflexão - Tem que incentivar o trabalho na vida dos filhos cedo. Para dar valor nas coisas obtida com o seu trabalho; Aos 14 anos. Responsabilidade e educação e profissionalismo; depois de terminar os estudos; $A$ partir dos 20 anos. Para eles terem um futuro melhor, em minha opinião a idade correta é de 15 anos; a parti dos quatorze anos de idade. Educação social e ter responsabilidade, a criança tem que aprender o valor do trabalho desde o momento em que passa entender e ajudar a família e esta ensinar auxiliando a criança em pequenas tarefas e não explorá-las sabendo que o trabalho é importante será um adulto melhor; 13 anos a importância e de estudar e aprender como são os trabalhos; os filhos tem que crescer, estudar para ter um futuro melhor; não tem idade correta para o trabaIho, temos que incentivar o trabalho na vida deles para que eles aprendam a dar valor em tudo que eles obter através do trabalho; 13 anos. Obter responsabilidade, comprometimento e maturidade, eu gostaria que eles estudasse ate si forma só depois procurar emprego; quando eles tiverem idade, e estudar para ter um trabalho melhor, no futuro; eu quero que eles estudar muito para se alguém na vida.

Segundo Saviani (2007, p. 152), o "trabalho e educação são atividades especificamente humanas. Isso significa que, rigorosamente falando, apenas o ser humano trabalha e educa”. Muitas das concepções foram de uma educação e trabalho desvinculados um do outro. Talvez esses sujeitos tenham essa concepção porque a escola e a sociedade acabam passando uma imagem cada vez mais setorizada da educação, ou seja, educação sendo separada não somente do tra- 
balho, mas também de outros momentos da vida, como saúde, segurança, lazer e outros acontecimentos da vida cotidiana. Faz-se necessário assim uma revisão da educação e do trabalho na constituição de uma sociedade mais justa, especialmente aqui, de uma sociedade camponesa.

Se a existência humana não é garantida pela natureza, não é uma dádiva natural, mas tem de ser produzida pelos próprios homens, sendo, pois, um produto do trabalho, isso significa que o homem não nasce homem. Ele forma-se homem. Ele não nasce sabendo produzir-se como homem. Ele necessita aprender a ser homem, precisa aprender a produzir sua pró- pria existência. (SAVIANI, 2007, p. 154).

Foi perguntado também se os pais gostariam de ter tido oportunidade de estudar por mais tempo. Todos responderam que sim. A necessidade de trabalhar e possivelmente a necessidade de se deslocar para a cidade para continuar os estudos podem ser levantados como um dos principais motivos para interrupção dos estudos. Entres os comentários se destacam: sim, gostaria mais não tive; Eu gostaria mais eu não tive a oportunidade de estudar, porque tive que trabalhar, para me manter; sim mais tive comesa a trabalhar; gostaria muito. Porque eu comecei a trabalhar muito nova, para me manter.

Esses comentários deixam latente a dívida histórica que o Estado possui com esses brasileiros e de certa forma explicam o crescente movimento por uma educação que aconteça no campo, que seja dos camponeses e respeitem o seu espaço de vida, território e lugar. O Estado apesar de reconhecer essa dívida histórica e esse direito, deixa transparecer que esses direitos expressos em leis, artigos, caputs e em linguagem jurídica ainda ficam presos no papel e acabam não se materializando na realidade vivida pelos sujeitos do campo. Existe ainda um cenário de escolas do campo com uma série de dificuldades, tanto no que tange a seus profissionais quanto a sua infraestrutura e materiais básicos para desenvolver uma educação de qualidade. Muitas escolas acabam por fechar as portas ou se aglomeram. O Estado, devedor-mor de uma educação de qualidade voltada ao campo e para os sujeitos do campo, vê como a melhor saída enviar muitos alunos do campo para a cidade, criando assim uma imposição cultural que transcende o simples fator locacional, como vem denunciando Souza $(2010 ; 2011 ; 2012)$.

\section{5 | À guisa de considerações finais}

Este trabalho contribui para a reflexão acerca das condições dos alunos que estudam nas escolas, e mais especificamente na escola palco da pesquisa, e a condição das pessoas que moram no campo. Nem tudo pode ser reduzido ao econômico, mas de certo essa condição acaba colocando em jogo os aspectos sociais e culturais desses sujeitos, que cada vez mais são subordinados a uma lógica externa ao campo. A cultura, as práticas e valores apresentados podem estar em risco de não existir nas próximas gerações, visto que cada vez menos esses sujeitos estão com suas práticas vinculadas ao campo. Está-se deixando de possuir o significado de substrato no qual se vive e se abstraem as condições de sobrevivência para se tornar apenas um local que se descansa e recuperam-se, ao lado de sua família, as forças para mais um dia de trabalho, que agora fica longe de casa.

A escola analisada ainda carece de muitas melhorias para que se torne de fato dos sujeitos do campo, ao invés de para o campo. Desta feita, como qualquer outra escola que deseja ser democrática, falta a participação dos pais e da comunidade para o seu fortalecimento. A escola no/do campo deveria ser espaço no qual os sujeitos do campo encontram os meios e as possi- 
bilidades para se libertar. Infelizmente, essa escola não oferece as condições mínimas para que esses sujeitos se integrem ao mundo digital e pelo visto não trabalha uma educação voltada para o trabalho e para a vida cotidiana na perspectiva de uma formação de um sujeito onilateral.

A imagem ainda muito presente na concepção dos alunos volta-se para atividades e afazeres típicos da cidade, como pôde ser observado nas escolhas futuras, como a profissão. Os alunos se baseiam em profissões que estão longe de serem voltadas para o desenvolvimento do campo. Talvez se esse futuro venha a se concretizar mais uma vez o campo estará fadado a perder uma parcela desses sujeitos. Cabe a organização desses sujeitos do campo, juntamente com os movimentos sociais, para que lutas sejam travadas no âmbito das políticas públicas e dos planos de governo para que seja possível a viabilização e o poder de escolha em permanecer no campo. O fortalecimento de aparelhos, como a escola e associações, é uma boa maneira de consolidar e estruturar equipamentos básicos que viabilizaram a consciência de classes e de sujeitos quanto a seres da cultura e consequentemente armarão de argumentos esses sujeitos para lutarem por seus direitos e melhores condições de vida no campo.

Muitos são os desafios, e haja fôlego ideológico e vontade de transformação, para que os anseios dos movimentos sociais e o projeto de educação do campo sejam materializados. Essa luta deve ser não apenas dos envolvidos, mas de todos aqueles que acreditam em uma educação pública emancipadora, de cunho popular, de qualidade e para todos. O primeiro passo é a quebra de preconceitos, de rotulações e de submissões que põem a educação do campo aquém das demais. O segundo é mão na massa, é práxis, é luta, é possibilitar autonomia para os indivíduos envolvidos, no sentido de condução própria de suas vidas. A ideologia a ser adotada é simples, o campo como espaço de vida. 


\section{Referências}

ARROYO, M. G. Educandos e educadores: seus direitos e o currículo. In: BEAUCHAMP, J.; PAGEL, S. D.; NASCIMENTO, A. R. (Org.). Indagações sobre currículo: educandos e educadores: seus direitos e o currículo. Brasília, DF: Ministério da Educação, 2007. Disponível em: $<$ http://portal.mec.gov.br/seb/arquivos/pdf/Ensfund/indag2. pdf>. Acesso em: 9 mai. 2014.

BRASIL. Atlas do espaço rural brasileiro retrata a realidade do campo no Brasil. 2012. Disponível em: <www.brasil.gov. br/economia-e-emprego/2012/10/atlas-do-espaco-ruralbrasileiro-retrata-a-realidade-do-campo-no-brasil>. Acesso em: 9 mai. 2014.

. Ministério da Educação. Diretrizes operacionais para a educação básica nas escolas do campo: CNE. Resolução CNE/CEB 1/2002. Diário Oficial da União, 9 de abril de 2002, Seção 1, p. 32.

Ministério da Saúde. Política de saúde para a população do campo. 2004. Disponível em: <http://dtr2004. saude.gov.br/susdeaz/instrumento/arquivo/12_Politica_ pop_campo.pdf>. Acesso em: 9 mai. 2014.

BENJAMIN, C.; CALDART, R. S. Projeto popular e escolas do campo: educação no campo - por uma educação básica do campo. Brasília, DF: Articulação Nacional por uma Educação Básica do Campo, 2000. 54 p. (Coleção por uma educação básica do campo, n. 3).

CALDART, R. S. Por uma educação do campo: traços de uma identidade em construção. In: KOLLING. E. J., CERIOLI. P. R., CALDART. R. S. Educação do campo: identidade e políticas públicas. Brasília, DF: Articulação Nacional por uma educação do campo, 2002a. p. 18-25. (Coleção por uma educação do campo, n. 4).

Ser educador do povo do campo. In: KOLLING, E. J.; CERIOLI, P. R.; CALDART, R. S. (Org.). Educação do campo: identidade e políticas públicas. Brasília, DF: Articulação Nacional por uma educação do campo, 2002b, 92 p. (Coleção por uma educação do campo, n. 4).

DECLARAÇÃO Final. Por uma política pública de educação do campo. In: CONFERÊNCIA NACIONAL POR UMA EDUCAÇÃO DO CAMPO, 2., 2004, Luziânia. Declaração... Luziânia, 2004

FANTE, C. Fenômeno bullying: como prevenir a violência nas escolas e educar para a paz. São Paulo: Verus, 2005. $224 \mathrm{p}$.

FERNANDES, B. M. Os campos da pesquisa em educação do campo: espaço e território como categorias essenciais. In: MOLINA, M. C. Educação do campo e pesquisa: questões para reflexão. Brasília, DF: Ministério do Desenvolvimento Agrário, 2006, p. 27-39.

FERNANDES, B. M.; CERIOLI, PL. R.; CALDART, R. S. Primeira conferência nacional "Por uma educação básica do campo".In: ARROYO, M. G.; CALDART, R. S.; MOLINA, M. C. (Org.). Por uma educação do campo. Petrópolis, RJ: Vozes, 2004

FREIRE, P. Ação cultural para a liberdade. Rio de Janeiro: Paz e Terra, 1981. 149 p.

. Carta de Paulo Freire aos professores. Estudos
Avançados, v. 15, n. 42, p. 259-269, 2001.

FUNDO NACIONAL DE DESENVOLVIMENTO DA EDUCAÇÃO. Clientela atendida pelo Pnae (senso escolar). 2013. Disponível em: <http://www.fnde.gov.br/programas/ alimentacao-escolar/alimentacao-escolar-consultas>. Acesso em: 26 maio 2014.

HENRIQUES, R. et al. (Org.) Educação do campo: diferenças mudando paradigmas. Ministério da Educação: Brasília, DF: 2007. Disponível em: <http://www.red-ler.org/ educacaocampo.pdf>. Acesso em: 9 maio 2014

INSTITUTO BRASILEIRO DE GEOGRAFIA E ESTATÍSTICA. Operação censitária. 2011. Disponível em: <http://www.ibge.gov.br/home/presidencia/noticias/guia do_censo_2010_operacao.php>. Acesso em 18 dez. 2013.

Pesquisa nacional por amostra de domicílios: um panorama da saúde no Brasil. Rio de Janeiro: IBGE, 2010.

MATEUS, C. Lan house e cibercafé. 2006. Disponível em: <http://www.verbojuridico.com/doutrina/tecnologia/ lanhouse_cibercafe.pdf>. Acesso em: 26 maio 2014.

NASCIMENTO, C. G. Educação do campo e escola família agrícola de Goiás: o caminhar da teimosia de um movimento social educativo. Revista Diálogo Educacional, Curitiba, v. 4, n. 8, p. 1-17, jan./abr. 2003. Disponível em: <http://www2.pucpr.br/reol/index.php/ DIALOGO?dd1=647\&dd99=view $>$. Acesso em 9 mai. 2014

Educação, cidadania e políticas sociais: a luta pela educação básica do campo em Goiás. Revista Iberoamericana de Educación, Madrid, Espanha, n. 33, v. 10, p. 1-16, 2004. Disponível em: <http://www.rieoei.org/ deloslectores/752Godoy.PDF>. Acesso em: 9 mai. 2014.

NASCIMENTO, J. A. S.; SILVA, J. K. T. Desigualdade socioeconômica no campo. In: INSTITUTO BRASILEIRO DE GEOGRAFIA E ESTATÍSTICA. Atlas do espaço rural brasileiro. Rio de Janeiro: IBGE, 2011.

OLIVEIRA, A. U. A agricultura camponesa no Brasil. São Paulo: Contexto, 1991.

SANTOS, G. A. N. C. Uma proposta pedagógica de abordagem ao tema bullying. Cadernos de Pós Graduação em Letras, v. 8, n. 1, p. 1-6, 2008. Disponível em: <www. mackenzie.br/fileadmin/Pos_Graduacao/Doutorado/ Letras/Cadernos/Volume 8/13-UMA PROPOSTA PEDAGOGICA_DE_ABORDAGEM AO TEMA BULLYING.pdf>. Acesso em: 26 maio 2014.

SANTOS, M. A natureza do espaço: técnica e tempo razão e emoção. São Paulo: EdUSP, 2012.

O espaço do cidadão. São Paulo: Studio Nobel, 2000. 142 p. (Coleção espaços).

Por uma outra globalização: do pensamento único à consciência universal. São Paulo: BestBolso, 2011. 143 p.

SAVIANI, D. Trabalho e educação: fundamentos ontológicos e históricos. Revista Brasileira de Educação, v. 12, n. 34, p. 152-180, jan./abr. 2007. Disponível em: <http:// www.scielo.br/pdf/rbedu/v12n34/a12v1234.pdf>. Acesso em: 9 mai. 2014 
SOUZA, F. E. As "geografias" das escolas no campo do município de Goiás: instrumento para a valorização do território do camponês?. 2012. 380f. Tese (Doutorado em Geografia) - Universidade Estadual Paulista "Júlio Mesquista Filho", Presidente Prudente, 2012.

Os colégios rurais agrupados na Espanha: espaços de fortalecimento do campesinato? Revista Nera, Presidente Prudente, ano 14, n. 18, p. 21-36, jan./jun. 2011. Disponível em: <http://revista.fct.unesp.br/index.php/ nera/article/viewFile/1603/1544>. Acesso em: 9 mai. 2014.

Uma geografia escolar para o fortalecimento da

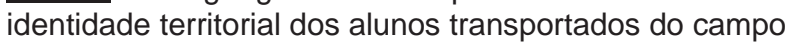

para a cidade no município de Goiás. In: ENCONTRO NACIONAL DOS GEÓGRAFOS, 16., 2010, Porto Alegre. Anais... São Paulo: Associação dos Geógrafos Brasileiros, 2010.

SOUZA, F. E.; FERNANDES, B, M. O papel da geografia escolar para o fortalecimento do campesinato no município da Cidade de Goiás. In: ENCONTRO DE GEÓGRAFOS DA AMÉRICA LATINA, 12., 2009, Montevidéu, Uruguai. Anais... Montevidéu, 2009.

WOORTMANN, E. F.; WOORTMAN, K. O trabalho da terra: a lógica e a simbólica da lavoura camponesa. Brasília, DF: Ed. Universidade de Brasília., 192 p. 